\title{
Método científico ao alcance de todos: uma análise da iniciação científica nos anos iniciais do ensino fundamental
}

\author{
Scientific method available to all: an analysis of scientific initiation in the early years of \\ elementary school
}

Daiane Martins Bocasanta*

\section{Resumo}

Este trabalho apresenta uma investigação que buscou problematizar a iniciação científica (IC) que cada vez mais precocemente passa a ser endereçada aos estudantes dos anos iniciais do ensino fundamental. Esse objetivo desdobrou-se nas seguintes questões de pesquisa: as crianças, estudantes dos anos iniciais do ensino fundamental, são assujeitadas à racionalidade moderna, em que a ciência ocupa um lugar privilegiado entre os saberes? De que forma isso ocorre? O referencial teórico em que se apoiou a pesquisa situa-se em uma abordagem pós-metafísica, especialmente nas teorizações de Michel Foucault e seus comentadores. O material de pesquisa foi composto por pôsteres apresentados no Salão UFRGS Jovem, regulamentos do evento, anotações de observações em diário de campo e um livro sobre metodologia científica para diferentes públicos. A metodologia de pesquisa utilizada situa-se na análise do discurso na perspectiva foucaultiana. Entre os resultados obtidos na pesquisa, observou-se que: a) a implementação precoce da IC visa à formação de sujeitos cujos interesses voltem-se para as carreiras científicas; e b) a IC desejável a ser implementada nas escolas de educação básica presta-se a treinar, educar e exercitar cada parte do corpo de potenciais candidatos a carreiras científicas, apesar de o material de pesquisa muitas vezes descrever a IC como uma forma de desenvolver a criatividade ou o pensar cientificamente como um pensar livre.

Palavras-chave: Anos iniciais. Iniciação científica. Michel Foucault.

\section{Abstract}

The present paper presents an investigation that attempted to problematize the Scientific Initiation (SI) that has become early addressed by the Early Grades of Elementary School. This goal unfolded in the following research questions: are the children, students of the Early Grades of Elementary Education, attached to Modern Rationality, where science occupies a privileged place among knowledge? How does this occur? The theoretical reference on which the research was based is situated in a post-metaphysical approach, especially in the Michel Foucault theories and his commentators. The research material consisted of posters presented at the Salão UFRGS Jovem, event regulations, field observations notes and a book on scientific methodology for different audiences. The used research methodology is situated in the Foucauldian perspective discourse analysis. Among the obtained research results it was observed that: a) the early implementation of SI aims the formation of subjects whose interests return to the scientific careers; b) the desirable Scientific Initiation to be implemented in the Basic Education schools lend themselves to train, educate and exercise each part of the body of the potential candidates for scientific careers, although the research material often describes the SI as a way for developing creativity or scientifically thinking as a free thinking.

Keywords: Early grades. Michel Foucault. Scientific initiation.

\author{
Recebido em 17/11/2017 - Aprovado em 23/02/2018 \\ http://dx.doi.org/10.5335/rep.v25i2.8176
}

\begin{abstract}
Doutora em Educação pela Universidade do Vale do Rio dos Sinos. Docente do Colégio de Aplicação da Universidade Federal do Rio Grande do Sul, lotada no Departamento de Humanidades, Área de Polivalência. E-mail: daianebocasanta@gmail.com
\end{abstract}


Será que qualquer estudante pode compreender e aplicar a metodologia científica sem complicação? Ou será preciso, para isso, ser um cientista? Acredito, e é por isso que escrevi este livro, que um estudante - do ensino fundamental à

pós-graduação - pode aplicar o método científico nos seus trabalhos escolares sem que para tanto necessite ter profundos conhecimentos científicos (AZEVEDO, 2013, p. XVII).

A epígrafe que abre esse trabalho faz parte do livro Metodologia científica ao alcance de todos, de Celicina Borges Azevedo. Essa obra, que faz parte do material de pesquisa aqui escrutinado, propõe-se a ser um manual capaz de oferecer a todos estudantes - desde os primeiros anos da educação básica à pós-graduação - subsídios para a utilização do método científico em trabalhos escolares. Como podemos observar no trecho citado anteriormente, o método científico, que antes era circunscrito à construção de trabalhos no meio acadêmico, passou a ser algo que todos podem/devem dominar, de preferência, desde a mais tenra idade. Como exploro mais adiante, essa ideia conecta-se diretamente à inserção, cada vez mais precoce, da iniciação científica (IC) nas salas de aula. Assim, o objetivo deste estudo foi problematizar a IC, que, cada vez mais, passa a fazer parte do cotidiano das salas de aula dos anos iniciais do ensino fundamental. Desse objetivo, desdobraram-se as questões de pesquisa aqui desenvolvidas: as crianças, estudantes dos anos iniciais, são assujeitadas à racionalidade moderna, em que a ciência ocupa um lugar privilegiado entre os saberes? De que forma isso ocorre?

$\mathrm{O}$ interesse pelo tema abordado surgiu ao iniciar minha caminhada docente no Colégio de Aplicação da Universidade Federal do Rio Grande do Sul (CAP/ UFRGS), Porto Alegre, RS, uma instituição que utilizava/utiliza a IC em seu currículo escolar desde o primeiro ano do ensino fundamental até a conclusão do ensino médio. Tive, então, curiosidade de saber se isso acontecia em outras instituições escolares do município. Desse modo, comecei a buscar informações em sites de escolas, visando a identificar aquelas que fizessem o mesmo tipo de trabalho realizado no CAP/UFRGS e a forma como ele era apresentado. O resultado dessa busca levou-me a constatar que, mesmo nomeada de diferentes modos, realizada desde a educação infantil, anos iniciais ou finais do ensino fundamental até o ensino médio, a IC já estava presente nas propostas pedagógicas de muitas escolas porto-alegrenses, tanto da rede pública quanto da rede privada. Passei a observar que o uso cada vez mais precoce da IC em salas de aula tem sido enaltecido na publicidade de instituições escolares como indicativo de um ensino de qualidade. O bom desempenho em eventos, como mostras e salões de IC de universidades, bem como a realização de feiras abertas à comunidade escolar, cada vez mais elaboradas, também têm servido como respostas a um exigente público que tem "direito" ao acesso à ciência, 
pois se vê "como um fator-chave a proposta de que, no século XXI, a ciência deva se converter em um bem compartilhado [...] e que o acesso ao saber científico se faça, desde muito cedo, como parte do direito à educação que têm todos os homens e mulheres" (MACEDO; KATZKOWICZ, 2003, p. 70). Essas constatações, além de aguçarem minha vontade de pesquisar sobre o tema, guiaram-me ao entendimento de que tinha em mãos questões pertinentes ao momento que vivemos no campo educacional. Sendo assim, destaco alguns excertos obtidos no levantamento inicial realizado:

A iniciação científica nos Anos Iniciais do Colégio de Aplicação da UFRGS ocorre em todas as turmas, desde a turma do I Ano do Ensino Fundamental de 9 anos até o final do Ensino Médio. Trata-se de uma iniciativa pedagógica baseada na ótica piagetiana da escola ativa, em que o trabalho em equipe a partir de assuntos de interesse das crianças faculta-lhes um desenvolvimento intelectual e moral. O primeiro, em função da atividade sistemática movimentada pela necessidade de produzir explicações para dúvidas e curiosidades infantis, que podem ser um mote inicial para, a partir das experimentações, estabelecer relações necessárias e suficientes, conhecer e compreender mais o mundo em que vivem. [...] As atividades de IC têm início no primeiro trimestre letivo e os trabalhos são inscritos anualmente no Salão UFRGS Jovem, realizado pela Pró-Reitoria da UFRGS, durante a semana acadêmica (COLÉGIO DE APLICAÇÃO DA UFRGS, 2017, não paginado).

Ensino Fundamental I

O trabalho desse segmento se propõe a desenvolver nos alunos as habilidades e capacidades nas dimensões cognitiva, física, afetiva, de relações interpessoais, estética, ética e de inserção social, promovendo o levantamento de hipóteses relativas ao conhecimento, a potencialização da imaginação e da criatividade. A iniciação científica e os projetos de trabalho utilizam metodologias diversas adequadas à faixa etária. As saídas de campo, vivências e experiências contemplam as áreas do conhecimento de forma lúdica e inspiradora para a construção do conhecimento (COLÉGIO MONTEIRO LOBATO, 2017, não paginado).

Anos Iniciais ( $1^{\circ}$ a $5^{\circ}$ ano EF)

[...] Iniciação Científica

O incentivo à pesquisa começa na sala de aula e visa desenvolver habilidades importantes para as atividades acadêmicas. Os estudantes realizam projetos de iniciação científica nas diferentes áreas do conhecimento e são incentivados a participar de salões e congressos. Por estarem inseridos no Campus da PUCRS, eles ainda vivenciam toda a estrutura do mundo acadêmico (COLÉGIO MARISTA CHAMPAGNAT, 2017, não paginado).

Como podemos observar, a IC é posicionada como uma marca diferencial das escolas, utilizada até mesmo para promovê-las. Atualmente, para além de informações em sites, em breve passeio pela cidade de Porto Alegre, é possível sermos interpelados pela publicidade elaborada em torno da IC que as escolas privadas espalham por outdoors e busdoors. No CAP/UFRGS, a IC destaca-se como algo que acompanha os alunos desde a sua entrada na escola, nos anos iniciais do ensino fundamental, até sua saída, no final do ensino médio. É descrita como uma 
atividade que parte dos interesses dos alunos, "movimentada pela necessidade de produzir explicações para dúvidas e curiosidades infantis", capaz, dentre outras coisas, de facultar ao aluno conhecimento e compreensão "do mundo em que vive".

A descrição presente no site do Colégio Monteiro Lobato, da mesma forma que aparece no texto do blog do projeto Unialfas (como é nomeado o segmento dos anos iniciais), do CAP/UFRGS, leva-nos ao entendimento de que tal atividade proporciona aos alunos o acesso às "áreas do conhecimento de forma lúdica e inspiradora para a construção do conhecimento". De forma análoga ao CAP/UFRGS, que destaca a participação anual de seus alunos no Salão UFRGS Jovem - ou Salãozinho, como é chamado no contexto da universidade -, o Colégio Marista Champagnat evidencia o incentivo dado aos seus alunos para a participação nesse tipo de evento, complementando que "por estarem inseridos no Campus da PUCRS, eles [os alunos] ainda vivenciam toda a estrutura do mundo acadêmico".

Podemos observar nesses excertos a recorrência de algumas enunciações sobre a IC voltada para os jovens estudantes dos anos iniciais. Entre algumas ideias que podemos identificar nesse material, estão as de que a IC é uma forma lúdica para as crianças, que são seres naturalmente curiosos, de que adquirir conhecimentos científicos proporciona o desenvolvimento dos indivíduos em diferentes dimensões, tais como cognitiva, social e moral, bem como de que a IC prepara os estudantes para a vida acadêmica - o que se espera que todos alcancem futuramente. Dominar conhecimentos científicos, assim como um "certo modo" de pensar cientificamente, aparece não apenas como atributos desejáveis, mas como inevitáveis. Aprender sobre ciência surge como um direito a que todos devem ter acesso, de preferência, desde a mais tenra idade. É possível conjecturar que a forma como as coisas estão colocadas posiciona hierarquicamente os conhecimentos científicos em um patamar. Com isso, poder-se-ia sugerir que tais recorrências acabam por instituir verdades a respeito da IC escolar. Por sua vez, essas verdades, constituídas por relações de poder/saber, produzem seus efeitos. A discussão de Foucault sobre essas relações é esclarecedora:

Há efeitos de verdade que uma sociedade como a ocidental, e hoje se pode dizer a sociedade mundial, produz a cada instante. Produz-se verdade. Essas produções de verdades não podem ser dissociadas do poder e dos mecanismos de poder, ao mesmo tempo porque esses mecanismos de poder tornam possíveis, induzem essas produções de verdades, e porque essas produções de verdade têm elas próprias, efeitos de poder que nos unem, nos atam. São essas relações verdade/poder, saber/poder que me preocupam. Então, essa camada de objetos, ou melhor, essa camada de relação, é difícil de apreender; e, como não há teorias gerais para apreendê-las, eu sou, se quiserem, um empirista cego, quer dizer, estou na pior das situações (FOUCAULT, 2012, p. 224). 
Aqui vale ressaltar que, apoiada nas formulações foucaultianas, essa escrita não compreende o poder como algo que se detenha ou que se aplique de cima para baixo. Para Foucault (1999), o poder somente é tolerável mascarando uma parte importante de si mesmo. Dessa forma, "seu sucesso está na proporção daquilo que consegue ocultar dentre seus mecanismos" (FOUCAULT, 1999, p. 83), ou seja, o funcionamento do poder não se dá pelo abuso. Nas palavras do filósofo francês:

E não somente porque o impõe aos que sujeita como, também, talvez porque lhes é, na mesma medida, indispensável: aceitá-lo-iam, se só vissem nele um simples limite oposto aos seus desejos, deixando uma parte intacta - mesmo reduzida - de liberdade? O poder, como puro limite traçado à liberdade, pelo menos em nossa sociedade, é a forma geral de sua aceitabilidade (FOUCAULT, 1999, p. 83).

Outra afirmação de Foucault que destaco acerca do poder é: "o poder não existe" (2008, p. 248). Com isso, o filósofo indicou que pensar no poder como algo que existe em algum lugar ou como algo que emana de um determinado ponto seria fazer uma análise enganosa, incapaz de levar em conta uma série de fenômenos (FOUCAULT, 2008). O poder, para Foucault, constitui "um feixe de relações mais ou menos organizado, mais ou menos piramidalizado, mais ou menos coordenado" (FOUCAULT, 2008, p. 248).

Entre outras coisas, Foucault afirmou que o poder seria coextensivo ao corpo social, não existindo, "entre as malhas de sua rede, praias de liberdades elementares" (2012, p. 243). Estando disseminadas e capilarizadas por todo o corpo social, as relações de poder seriam "intrincadas com outros tipos de relação (de produção, de aliança, de família, de sexualidade) que desempenham um papel ao mesmo tempo condicionante e condicionado" (FOUCAULT, 2012, p. 243).

Assim, ao deparar-me com as recorrências antes mencionadas, passei a questionar a "naturalização" com que está sendo tratada a inserção cada vez mais precoce da IC nos currículos escolares de diferentes escolas e nas tramas de poder que sustentam essa "naturalização". Ao refletir sobre o tema escolhido para abordar na pesquisa, senti-me interpelada pelas formulações de Michel Foucault, visto que, de sua ótica, a atividade científica conforma um dispositivo de poder-saber, apoiado pela racionalidade de seus discursos e suas práticas (DÍAZ, 2007). Essa racionalidade seria construída por princípios lógicos e pela obrigação de submeter suas hipóteses à comprovação empírica e teria como pretensão atravessar os laboratórios e expandir-se para outras formas de vida. Desse modo, o conhecimento científico, aos poucos, foi tomado como garantia de tudo aquilo que se deve considerar como verdadeiro (DÍAZ, 2007).

Valero (2013) faz uma análise da educação matemática escolar similar à realizada neste estudo acerca da IC. Trazer tal analogia se faz importante, tendo em 
vista que a matemática ocupa um lugar estratégico em relação ao desenvolvimento da tecnociência. Segundo a autora, a ideia de que o conhecimento científico e matemático é importante para o bem-estar da sociedade tornou-se bastante comum nos dias de hoje. Essa ideia remonta ao século XX, com o surgimento da narrativa que conecta superioridade econômica e desenvolvimento da competência matemática do cidadão. Assim, todos teriam aprendido bem a lição: pais, políticos, empresários, professores e, até mesmo, as crianças (VALERO, 2013). Nas palavras de Valero:

Quem iria questionar a necessidade de cientistas, engenheiros e matemáticos para produzir o grande progresso tecnológico que fez o mundo atingir este alto ponto de desenvolvimento - e de decadência também? A ideia de que a matemática - assim como a ciência -, com todas as suas aplicações em tecnologia, é o motor para alcançar as promessas da Modernidade e de que, portanto, seu ensino e sua aprendizagem são fundamentais para a constituição dos sistemas escolares de massa é tão antiga - ou nova - quanto o foi no final do século XIX (2013, p. 1, tradução nossa). ${ }^{1}$

Portanto, pensar em um currículo escolar sem matemática - e, por que não dizer, sem ciências ou IC - tornou-se algo impossível. Durante boa parte do século XX, a preocupação principal dos matemáticos com a educação era formar uma elite intelectual altamente competente (VALERO, 2013). Essa preocupação era canalizada para a qualidade e não para a quantidade de pessoas capazes de proporcionar um conhecimento altamente valorizado a outras disciplinas das ciências puras e da crescente quantidade de campos da engenharia científica e aplicada (VALERO, 2013). De maneira análoga à que observei no material de pesquisa escrutinado em relação a IC -, Valero (2013) salienta que a ideia de que a matemática deve ser para todos é bastante recente, tendo seu início datado no final do século XX. Essa ideia viria na garupa de um pensamento que vê na matemática a chave para garantir a competitividade nacional na economia global do conhecimento. Isso, tal como alerta a autora (VALERO, 2013), não seria apenas uma declaração inocente de bons desejos para o futuro. Tal movimento teria a ver com uma determinada visão normativa, cuja função seria orientar propostas políticas e, sobretudo, intervenções baseadas em pesquisas para ampliar o alcance de todos a um conhecimento altamente valorizado como a matemática.

Em sua análise, apoiada em Foucault, Valero (2013) examina o enunciado "educação matemática é para todos", argumentando que ele funcionaria como um dispositivo discursivo que constrói como norma a necessidade de fazer sucesso na aprendizagem da matemática. Em relação à $\mathrm{IC}$ em sala de aula, tal ideia também se faz presente, como podemos observar, na manchete do artigo de capa da Revista Nova Escola, de setembro de 2013, Foco na pesquisa: "as aulas de Ciências devem instigar a curiosidade dos alunos. Com ferramentas como a observação, a experimentação e a leitura, eles vão aprender a explicar o que ocorre à nossa volta" 
(FERREIRA, 2013, p. 36). A afirmação "eles vão" não abre espaço para que alguém esteja fora. Todos devem conseguir "aprender e explicar".

Um trabalho que se aproxima do que realizo, problematiza o uso do método científico com alunos da educação básica. A partir especialmente da análise de excertos de livros didáticos de Ciências e de Física voltados respectivamente para os ensinos fundamental e médio, Moreira e Ostermann destacam que "o método científico é interpretado como um procedimento definido, testado, confiável para se chegar ao conhecimento científico: consiste em compilar 'fatos' através de observação e experimentação cuidadosas [...]” (MOREIRA; OSTERMANN, 1993, p. 108). Em sua analítica, os autores enfatizaram que os livros didáticos geralmente veiculam uma visão de certo modo rígida e estruturada do método científico (MOREIRA; OSTERMANN, 1993). Em suas conclusões, Moreira e Ostermann (1993) indicam que a ciência é produzida por indivíduos e que, portanto, pode sofrer a interferência de sentimentos e pensamentos. Assim, em vez de se ensinar um método científico que não existiria de fato, sugerem o ensino de procedimentos científicos. Uma aproximação possível entre o trabalho aqui discutido e o produzido por Moreira e Ostermann (1993) seria a problematização do uso do método científico na educação básica. Entretanto, vale ressaltar que, diferentemente daquele trabalho, o que estruturei, especialmente pela perspectiva teórica em que se insere, não oferece nenhuma prescrição a partir das discussões tecidas.

Outro trabalho que destaco toma as feiras de ciências como objeto de estudo. A dissertação de mestrado em Educação para a Ciência, de Renata Duarte Zuliani (2009), aproxima-se da investigação apresentada, principalmente por conta do público eleito para ser participante da pesquisa, ou seja, professores dos anos iniciais do ensino fundamental. Zuliani (2009) conta que precisou assumir, em uma escola onde lecionava, turmas na disciplina de ciências, mesmo sem ter formação específica para tal. Uma das solicitações dos alunos era que se realizasse uma feira de ciências, à qual ela se dedicou durante o ano letivo, envolvendo toda a escola, inclusive as turmas dos anos iniciais. Por não ser especialista na área de ciências, a autora considerou que "o caminho percorrido até a apresentação em praça pública foi árduo” (ZULIANI, 2009, p. 15).

As questões orientadoras do estudo foram: "quais saberes foram utilizados para a realização da Feira de Ciências?" e "quais foram os critérios utilizados na escolha desses saberes?" (ZULIANI, 2009, p. 20). A autora entrevistou os professores e ofereceu-lhes formações na área de sua investigação. Entre os resultados da pesquisa, Zuliani (2009) apontou a falta de preparo dos professores polivalentes para o trabalho com o ensino de ciências, mas, ao mesmo tempo, essa "falta de saberes" foi a mola propulsora para que buscassem superar os desafios propostos na pesquisa. 
Alguns trabalhos, como o produzido por Carlos Eduardo Lira Silva (2008), tomam como objeto de pesquisa clubes de ciências. Silva (2008) investigou as concepções de ciências de uma monitora do Clube do Pesquisador Mirim do Museu Paraense Emílio Goeldi, buscando entender, a partir da estruturação das atividades e das interações com os participantes, como suas concepções repercutiram na prática pedagógica e que oportunidades davam aos pesquisadores mirins para construírem concepções de ciências (SILVA, 2008). Nas entrevistas realizadas com a monitora, o autor identificou concepções que se aproximaram "do empirismo-indutivismo enfatizando a idéia de descoberta da verdade -, de uma ciência que sana os problemas socio-ambientais, que evoluiu a partir dos mitos, embora também tenha apresentado uma visão de ciência como atividade não rígida, não elitista e de desenvolvimento colaborativo" (SILVA, 2008, p. 59). Essa pesquisa, de certa forma, envereda pelos caminhos do questionamento da neutralidade da ciência, o que é uma das aproximações existentes entre tal investigação e a por mim realizada.

Nessa breve introdução, apresentei o objetivo, a problematização e algumas pesquisas, naquilo em que se aproximam ou se afastam da que desenvolvo. $\mathrm{Na}$ próxima seção, abordo os caminhos empíricos dessa investigação.

\section{Da empiria}

Como já destacado, a IC ocorria/ocorre em todas as turmas do CAP/UFRGS. Nas turmas de anos iniciais, a IC, além de ser um fio condutor das atividades realizadas em sala de aula, ocupa pelo menos três períodos semanais na grade de horário das turmas. Nesses momentos, cada turma é atendida simultaneamente por dois ou três professores. As pesquisas realizadas na IC apresentam variados períodos de duração e muitas vezes são inscritas e apresentadas no Salão UFRGS Jovem. ${ }^{2}$ Em meus primeiros dias de trabalho na instituição, no ano de 2011, chamou-me a atenção a existência de um feixe de pôsteres encostados em um canto da sala de professores dos anos iniciais, que, como vim a saber dos colegas mais antigos, teriam sido produzidos nas aulas de IC, inscritos e apresentados em diferentes edições do evento.

Passei, então, a abrir esses pôsteres no chão da sala de professores e a fotografar um a um. Havia a minha disposição um conjunto com mais ou menos vinte cartazes, todos produzidos por alunos e professores do $1^{\circ}$ ao $5^{\circ}$ ano. Em um primeiro momento, buscava, nesse material, indicações que me ajudassem a entender como era realizada a IC nos anos iniciais da escola, tendo em vista que, em minhas experiências anteriores, nunca havia trabalhado dentro dessa perspectiva. Entretanto, a maneira como esse material era composto acabou provocando em parte os questionamentos que foram a gênese deste estudo. 
Primeiramente, pensei que apenas os pôsteres seriam suficientes para a realização da pesquisa. Assim, passei a procurar neles a presença do método científico na elaboração dos textos apresentados. Foi possível observar certa regularidade nos passos descritos na maior parte das investigações presentes nos cartazes. Apesar de fornecer importantes indícios da utilização do método científico com as crianças, essa regularidade por si só não era suficiente para compreender as condições de possibilidade para a emergência desse acontecimento. Tendo em vista essa constatação, percebi que deveriam existir exigências, na organização do evento em que os pôsteres foram apresentados, conformando os trabalhos. Isso guiou-me para os regulamentos de diferentes edições do Salão UFRGS Jovem.

Por último, deparei-me com o livro antes citado, Metodologia científica ao alcance de todos (2013), de Celicina Azevedo. Nessa obra, a autora assim descreve sua intencionalidade: "[...] quero, em primeiro lugar, incentivar o aluno a observar o mundo em sua volta e a se perguntar por que as coisas acontecem" (AZEVEDO, 2013, p. 17). A continuação do argumento defende que o livro pode ajudar o estudante a não ter medo de expor suas perguntas e o professor a não se sentir obrigado a saber a resposta de tudo. Nesse contexto, Azevedo (2013) convida o leitor a "abrir sua mente", eliminando os bloqueios que possam impedi-lo "[...] de ver as coisas como elas verdadeiramente são, aliando a isso o conhecimento que [...] irá adquirir lendo este livro, a aplicação do método científico passará a ser uma questão de pura lógica e bom senso" (AZEVEDO, 2013, p. 18). Ou seja, o livro foi trazido à análise por abordar uma ideia recorrente ao se falar em IC no espaço escolar: a inevitabilidade do método científico. Tal inevitabilidade, como podemos observar no excerto transcrito, faz com que o uso desse método seja considerado como o caminho mais racional e, nas palavras da autora, "uma questão de pura lógica e bom senso". O conjunto, portanto, formado pelos pôsteres a que tive acesso, pelos regulamentos do Salãozinho e pelo livro de Celicina Azevedo, bem como por anotações em diário de campo, acabou conformando o material empírico desta investigação.

Nesse sentido, o exercício analítico empreendido baseou-se na discussão foucaultiana sobre discurso e enunciado, presente, em especial, nas obras Arqueologia do Saber (2002) e A ordem do discurso (2001). Para Foucault, os discursos seriam formados por um conjunto de enunciados, isto é, "práticas que formam sistematicamente os objetos de que falam" (2002, p. 56). Como destacam Wanderer e Schefer, "ao estudar discursos, nessa perspectiva, os pesquisadores buscam analisá-los por aquilo que dizem e pelas regras que os geram, não se prendendo aos significados dos signos que os compõem" (2016, p. 34). Nesta discussão, então, a noção de enunciado ganha centralidade. Como situa Deleuze (2006), apoiado em Foucault, os enuncia- 
dos não seriam palavras, frases ou proposições, mas formações que se fazem visíveis quando os sujeitos das frases, os objetos da proposição e os significados das palavras mudam de natureza. Isso ocorre quando esses elementos tomam o lugar do "diz-se", distribuindo-se, dispersando-se na espessura da linguagem. No caso desta pesquisa, podemos exemplificar isso ao observar o surgimento da IC nos anos iniciais do ensino fundamental como um fato recente, conectado às mudanças substantivas ocorridas no cenário socioeconômico e tecnocientífico internacional que suscitaram mudanças nas estratégias governamentais, visando a posicionar o país em condições de competir com outras nações. Tal conjunção de fatores, articulados com outras condições de possibilidade, criou uma atmosfera favorável para que passassem a circular com maior intensidade enunciações que situam a centralidade do conhecimento científico no currículo escolar como algo indispensável e inevitável.

Neste ponto, vale a pena destacar que adotar uma atitude metodológica foucaultiana nos leva a dirigir nossa atenção à linguagem como produtora de discursos e, nesse sentido, como inseparável das práticas institucionais de qualquer setor da vida humana (FISCHER, 2012). Ademais, refletir sobre os ditos que compõem o material da pesquisa sob uma abordagem foucaultiana é uma ação que não ignora nem as relações de poder que os produzem e atravessam, nem sua historicidade. Como aponta Fischer (2012), ao lembrar-nos de que prestar atenção à linguagem como constitutiva e constituída de práticas e de sujeitos não é uma invenção de Foucault, o diferencial apresentado pelo instrumental oferecido pelo filósofo francês é “[...] que ele insiste fortemente na produtividade 'positiva' da linguagem e dos discursos, naquilo que os discursos produzem historicamente, na vida das sociedades, do pensamento, dos sujeitos" (FISCHER, 2012, p. 104).

\section{A iniciação científica produzindo "pequenos cientistas"}

Como já mencionado, além de ocupar três períodos semanais da carga-horária em todas as turmas de anos iniciais do CAP/UFRGS, a IC geralmente acontece com a atuação de mais de um professor por turma. Nas turmas dos menores, as questões de pesquisa geralmente são escolhidas pela maioria da turma, constituindo um único projeto investigativo por vez que pode tanto durar alguns poucos meses quanto o ano inteiro. Com as crianças maiores, o funcionamento pode ser o mesmo ou, ainda, a organização pode ocorrer em torno de interesses de estudo de pequenos grupos ou mesmo individualmente.

A escolha das questões de pesquisa a serem estudadas pode ser feita de diferentes modos, como, por exemplo, a partir de atividades disparadoras. Essas atividades podem ser filmes, livros, exposições, saídas de campo, algum objeto ou 
informação trazida por algum estudante, etc. No caso da instituição em questão, era comum, há um tempo atrás, as professoras utilizarem uma animação, chamada Sid, o cientista - que analiso brevemente a seguir -, para os estudantes observarem coisas que despertassem sua atenção.

Ao examinar essa animação, um aporte ao qual as crianças tinham acesso tanto na escola quanto em casa, não pude deixar de perceber o quanto ela também atuava na fabricação de determinados modos de pensarmos a IC voltada para o público infantil, bem como estava intimamente imbricada no processo de fabricação dos sujeitos escolares. Observando esse material midiático, percebi que ele toma as crianças como seres curiosos e nomeia-as como "pequenos cientistas", conforme argumento a seguir.

Sid, o cientista, produzida por The Jim Henson Company e KCET/Los Angeles, é uma animação exibida no Brasil a partir de 2009. Tendo um enfoque científico, direcionado a diferentes temas de interesse das crianças em idade pré-escolar, a série, de certa forma, "didatiza" a ciência para as crianças pequenas (RIPOLL; WORTMANN, 2012). Os episódios desse desenho animado geralmente seguem um mesmo roteiro. Sid, protagonista da animação, segundo a descrição apresentada no site do canal Discovery Kids Brasil, faz "duas coisas dignas de um cientista perfeito: observa atentamente o mundo ao seu redor e faz um monte de perguntas" (DISCOVERY KIDS LATIN AMERICA, 2012, não paginado). Todos os dias, ao acordar pela manhã, Sid observa algo que o faz formular alguma questão científica, como: por que uma banana se deteriora.

Diariamente, a questão criada por Sid é levada para o café da manhã com sua família, formada pela mãe Alicia, o pai Mort e o irmão Zack, um bebê. Nesse momento, os pais fornecem algumas informações superficiais sobre o tema levantado por Sid, utilizando, inclusive, o computador, mas sempre concluindo que na escola ele poderá investigar melhor o que deseja saber. Já, na escola, Sid encontra seus colegas e faz uma enquete sobre o assunto em questão, até que a professora, tia Susie - que ajuda a realizar experimentos de verdade e, com isso, "faz com que a ciência seja muito mais divertida" -, chama todos para a roda, e Sid levanta a questão trazida de casa. Depois, ela convida os alunos, que denomina "cientistas", a irem ao "superlaboratório", que nada mais é do que um balcão em outra parte da sala de aula. Já, na bancada, Sid convida a criança telespectadora a também fazer uma experiência igual, dizendo: "você é cientista, pode fazer isto também!". Subitamente, o desenho cede lugar para imagens de uma sala de aula "normal", em que pessoas de verdade fazem a mesma experiência da turma da animação.

Voltando ao desenho animado, os alunos registram suas impressões em seus cadernos, que são revisadas pela professora. Ao final da aula, a avó de Sid - que, 
"assim como a grande maioria das avós de hoje, [...] participa muito da vida de seu neto" - busca-o na escola e escuta o que ele aprendeu, fazendo ligações com fatos cotidianos e algumas "histórias de antigamente". Ao que parece, no desenho, a ciência ocupa um lugar de destaque no dia a dia da família e da escola, e as crianças passam a ser tratadas como "pequenos cientistas".

Essa animação nos ensina sobre as dinâmicas familiares e escolares, mas, sobretudo, sobre "uma ciência que exige de seus praticantes atributos especiais, que os encaixem em uma convencional racionalidade, e uma ciência divertida, que se faz com alegria e descontração e ao nível da escola" (RIPOLL; WORTMANN, 2012, p. 10). Além disso, seu foco está em informações testadas, comprovadas e, por isso mesmo, científicas de nossas vidas cotidianas, configurando, assim, uma ciência útil (RIPOLL; WORTMANN, 2012).

De certo modo, podemos dizer que essa "propagação" de ideias que remetem à necessidade crescente de formar pessoas capazes de pesquisar, "cientistas" desde a mais tenra idade, relaciona-se diretamente a uma das reflexões elaboradas por Noguera-Ramírez (2011). Para o autor, o conhecimento, em nossa sociedade pós-capitalista, ocupa um lugar de extrema relevância, o que implica uma nova forma de pensarmos a educação, como algo que deixa de ser um monopólio das escolas (NOGUERA-RAMIREZ, 2011). Ele destaca que o relatório apresentado à Organização das Nações Unidas para a Educação, a Ciência e a Cultura (UNESCO) pela Comissão Internacional sobre Educação para o Século XXI, sob a presidência de J. Delors, demarca que o ingresso para o século XXI se daria pelo conceito de "educação ao longo da vida". Tal conceito supõe a capacidade de "aprender a aprender", visando a aproveitar todas as possibilidades ofertadas pela educação permanente (NOGUERA-RAMIREZ, 2011). O relatório citado marcaria a passagem do privilégio da instrução ou do ensino para a aprendizagem (NOGUERA-RAMIREZ, 2011). Assim, o acento muda do ensino para a aprendizagem. A educação deixa de ser uma função estatal para confundir-se com a própria sociedade. A sociedade educaria, ofertaria múltiplas e permanentes oportunidades educativas para seus cidadãos, porém também demandaria e consumiria educação (NOGUERA-RAMIREZ, 2011). Essa nova conformação, em que a educação deixa de ser uma obrigação para transmutar-se em uma necessidade, "um direito" e até mesmo uma exigência - passagem da obrigação estatal para a responsabilidade pessoal -, intitulou-se "cidade educativa” (NOGUERA-RAMIREZ, 2011). Nesse ínterim, entendo que a crescente ênfase na formação de "pequenos cientistas", de pessoas capazes de pesquisar, que possam todo o dia e sempre, a qualquer momento, por uma atividade corriqueira em dúvida que possibilite colocar em prática sua capacidade de "aprender a aprender", está completamente ligada às questões que assinala Noguera-Ramírez (2011). 
Nessa perspectiva, há uma ênfase na formação de um Homo discentis, ou seja, como consta em um dos documentos do Ministério da Ciência, Tecnologia, Inovações e Comunicações, um "Homo aprendiz permanente, definido por sua condição de ser um aprendiz ao longo da sua vida, ou melhor, um Homo que, para ser tal, deve aprender permanentemente" (BRASIL, 2001, p. 17). Assim, como antes assinalava, parece-me que o que está em jogo no modo de enfocar a IC escolar dos anos iniciais do ensino fundamental é investir no autogoverno dos sujeitos, tornando-os indivíduos que "aprendem a aprender" todo o tempo, tendo na aquisição do instrumental do método científico uma linha de pensamento e uma lógica de organização de sua forma de pensar.

Popkewitz, Olsson e Petersson (2009) também abordam a sociedade da aprendizagem, entendida como uma vida moral organizada em torno de uma contínua inovação, sem um ponto de chegada. Nela, os aprendentes seriam os cosmopolitas, ou seja, pessoas cujas vidas seriam guiadas pela adesão à mudança e à inovação contínuas (POPKEWITZ; OLSSON; PETERSSON, 2009). Em outras palavras, nessa sociedade, os sujeitos teriam seu presente regulado constantemente em nome de um futuro promissor.

O governo de si é enfatizado de diferentes modos na formação do sujeito cosmopolita, que se torna simultaneamente responsável pelo progresso social do mundo e por sua própria realização pessoal (POPKEWITZ; OLSSON; PETERSSON, 2009). A aprendizagem permanente e o consequente desenvolvimento da capacidade de resolver problemas seriam as chaves desse processo, bem como aquilo que se deveria perseguir. Tais reflexões direcionam-nos para o entendimento de que a implementação cada vez mais precoce da IC nas instituições escolares visa a formar esse indivíduo cosmopolita que Popkewitz, Olsson e Petersson (2009) nos apresentam e que é, ao mesmo tempo, o sujeito capaz de aprender a aprender de que nos fala Noguera-Ramírez (2011). O material escrutinado nesta investigação indica a predominância da ideia de que a IC realizada desde o início do processo de escolarização teria um impacto positivo tanto na vida pessoal dos sujeitos a ela submetidos quanto no progresso da sociedade.

As questões destacadas fizeram-me repensar minhas próprias práticas docentes e ideias que estavam em mim naturalizadas, tal como o ideal de sujeito a ser formado - muito parecido com o cosmopolita -, que eu jamais questionara. Assim, dou-me conta de que eu mesma sou um exemplo de que não apenas a conduta dos escolares está sempre sendo gerenciada, mas também o professor acaba tomando para si algumas narrativas como verdades incontestáveis. 


\section{Os pôsteres e o Salão UFRGS Jovem}

Em 2006, a Universidade Federal do Rio Grande do Sul realizou o I Salão UFRGS Jovem, em conjunto com o XVIII Salão de Iniciação Científica e a XV Feira de Iniciação Científica. Participam desse evento diversas escolas, tanto da rede pública quanto da rede privada. Entre os objetivos, o Salão UFRGS Jovem busca:

a) divulgar pesquisas realizadas pelos alunos da Educação Básica e da Educação Profissional Técnica;

b) incentivar a investigação científica no contexto educacional;

c) oportunizar a integração entre a universidade e a comunidade escolar;

d) fomentar atividades de cunho científico e tecnológico para alunos e professores (UNIVERSIDADE FEDERAL DO RIO GRANDE DO SUL, 2017).

Voltada para a educação básica, a participação no salão conta com estudantes desde a educação infantil até o ensino médio, sempre orientados por um professor da instituição de origem. Destaca-se, no regulamento do evento, a proximidade entre suas exigências e aquelas que temos visto em eventos científicos voltados para os públicos da graduação e da pós-graduação. No documento que regulamentou o XII Salãozinho, estava expressa a necessidade de se enviar um resumo sobre a pesquisa a ser apresentada, construído com base em uma série de critérios que definiam sua formatação, sua estrutura textual (com objetivos, metodologia, resultados obtidos até o momento ou conclusões), bem como "clareza e adequação da linguagem do texto diante da abordagem científica" (UNIVERSIDADE FEDERAL DO RIO GRANDE DO SUL, 2017, não paginado). A inadequação a tais critérios incorria na possibilidade de o trabalho não ser considerado apropriado para participação no salãozinho. Assim, o regulamento do XII Salão UFRGS Jovem indicava que, após a inscrição do resumo, este passaria pela avaliação de uma comissão, composta por professores da UFRGS, acompanhados de pós-graduandos da universidade.

Podemos observar certa hierarquização entre quem tem legitimidade para atribuir ou não status de cientificidade aos trabalhos a serem aceitos para apresentação no evento. Primeiro, o professor, pois, sem seu aval, o aluno não pode inscrever sua pesquisa no salãozinho. Acima do docente, há um grupo de pessoas que pode ou não certificar a cientificidade da investigação do estudante: os professores/pesquisadores universitários e seus estudantes, isto é, os pós-graduandos. Para serem consideradas como trabalhos de cunho científico, as investigações de alunos da educação básica, tanto daqueles que há pouco iniciaram seu processo de escolarização na educação infantil quanto dos que se aproximam de um possível ingresso no mundo acadêmico, já concluindo o ensino médio, devem passar por 
muitas instâncias. Nelas, seja naquilo que definem os manuais que pretendem ensinar professores de crianças pequenas a introduzirem a IC em sala de aula, seja em eventos que certificam ou não a cientificidade do trabalho realizado, há o dedo do expert. Paraíso (2005) discute, em um de seus estudos, que tem sido comum posicionar a educação escolar como um problema de diferentes áreas, tais como a Psicologia, a Economia e a Administração, cabendo sempre o olhar do especialista - o expert - na busca de soluções.

Ao ser pensada como um problema, a educação escolar torna-se necessitada de soluções que demandam a atuação de profissionais de diversas áreas (PARAÍSO, 2005). Conforme Paraíso, "por meio de diferentes estratégias, portanto, os problemas e soluções para a educação são apresentados por especialistas instalados nos órgãos governamentais, nos institutos de pesquisa, nas universidades, na mídia, etc." (2005, p. 175). No âmbito desta pesquisa, podemos observar que o problema da educação é posicionado junto com a adaptação à "nova ordem mundial”, no que diz respeito ao campo da ciência, da tecnologia e da inovação.

Isso coloca em evidência aquilo que Miller e Rose (1990) denominam expertise, entendido como "[...] a autoridade atribuída a determinados agentes e formas de julgamento com base em suas alegações de que possuem verdades especializadas e poderes raros" (1990, p. 2, tradução nossa). ${ }^{3}$ Os experts são aqueles profissionais autorizados a falar sobre algo. As instituições acabam, então, posicionando alguns desses experts para falar sobre determinados problemas e soluções para a educação e desautorizam outros (PARAÍSO, 2005).

Cabe refletir sobre quem é autorizado a definir quais trabalhos são científicos o suficiente ou não para constarem entre aqueles que serão apresentados no Salão UFRGS Jovem. Não há uma menção clara sobre a participação de representantes dos professores da educação básica - que de fato fazem pesquisas com seus alunos e conhecem suas especificidades - na seleção dos trabalhos. O papel do professor que atua na educação básica resume-se a fazer a pesquisa com seus alunos e a, posteriormente, submetê-la ao crivo daqueles que estão posicionados como os que podem dizer se ela apresenta um determinado grau de cientificidade que lhe permita estar entre os trabalhos divulgados em um salão de IC. A expertise como professor de crianças ou de adolescentes parece não ser levada em conta em prol da voz daqueles que podem conferir realmente o grau de cientificidade necessário aos trabalhos inscritos no evento: os professores pesquisadores e os estudantes de pós-graduação. É possível entender isso como um modo de direcionar condutas, no sentido de cada vez mais aproximar o processo educativo da educação básica do modelo presente no ensino superior. Tal fato relaciona-se ao argumento de Miller e Rose: 
[...] sustentamos que as capacidades de autorregulação dos sujeitos, formadas e normatizadas em grande parte através dos poderes da expertise, tornaram-se os principais recursos para modernas formas de governo e estabeleceram algumas condições cruciais para governar de forma democrática e liberal (1990, p. 2, tradução nossa). ${ }^{4}$

Desse modo, os vulcões feitos com argila ou as maquetes do sistema solar montadas com bolinhas de isopor e tinta têmpera, que antes disputavam atenções nas feiras de ciências escolares, hoje cedem lugar a um texto elaborado de acordo com um modelo predeterminado, que prevê, dentre outras coisas, uma minuciosa descrição de cada etapa da investigação, de acordo com os manuais de metodologia de pesquisa, como o escrito por Renè Descartes. Então, podemos pensar que, no "início do século XXI, o pensamento científico ainda tem raízes no século XVII, apoiando-se principalmente nas concepções de René Descartes, Galileu e Francis Bacon" (BORGES, 2007, p. 31). ${ }^{5}$

O Salão UFRGS Jovem, ainda que voltado para o público da educação básica, é um evento nascido no âmbito da universidade. A primeira edição ocorreu em 2006, como consequência de uma mostra realizada por alunos da educação básica durante a semana acadêmica do ano anterior. Sendo ligado à universidade, tal como venho destacando ao longo desta seção, é possível observar, em suas características e no regulamento do evento, aproximações bastante pronunciadas com a racionalidade do mundo acadêmico, adotado como um modelo a ser alcançado. A universidade é tomada como o topo do processo de escolarização. Nesse sentido, a educação básica é entendida como uma etapa preparatória para a chegada à universidade, e a participação no salãozinho é pensada como uma forma a mais de preparar-se para o ingresso no ensino superior. Isso é possível observar no regulamento da primeira edição do evento:

Em 2006, integrado ao XVIII Salão de Iniciação Científica e à XV Feira de Iniciação Científica, eventos anuais do calendário acadêmico da UFRGS, realiza-se o I Salão UFRGS Jovem, um espaço multidisciplinar para a divulgação das atividades de iniciação científico-tecnológicas, realizadas por alunos e professores da Educação Básica, nas escolas.

Neste sentido, ao conferir estatuto de Salão ao evento UFRGS Jovem, a Pró-Reitoria de Pesquisa da UFRGS (PROPESQ-UFRGS) ratifica a necessidade de cada vez mais se ampliar a divulgação das atividades de iniciação científico-tecnológicas oportunizadas às crianças e aos jovens no âmbito das escolas, portanto, numa etapa anterior a de se tornarem alunos universitários (UNIVERSIDADE FEDERAL DO RIO GRANDE DO SUL, 2013, não paginado, grifo nosso).

Os trabalhos de crianças pequenas passam por tribunais da verdade, seja ao serem inscritos - quando podem ou não ser aceitos por uma determinada comissão -, seja ao serem avaliados durante o evento. Sobre a premiação, no regulamento consta que: "o trabalho premiado receberá troféu como Destaque UFRGS Jovem 
Pesquisador - 2017" (UNIVERSIDADE FEDERAL DO RIO GRANDE DO SUL, 2017, não paginado). Assinala-se que tal avaliação se dá em duas instâncias: avaliação do pôster impresso e avaliação da apresentação oral. Os critérios na primeira instância são: "a) conteúdo e abordagem científica; b) clareza textual; e c) aspecto visual (imagens, fonte do texto, dimensões, layout)" (UNIVERSIDADE FEDERAL DO RIO GRANDE DO SUL, 2017, não paginado). Para a segunda instância, a avaliação passaria pela: "a) clareza na apresentação dos objetivos, da metodologia, dos resultados e das conclusões do trabalho; b) entendimento do(s) aluno(s) apresentador(es) diante do conteúdo pesquisado; e c) apresentação oral de no máximo 10 minutos, junto ao pôster" (UNIVERSIDADE FEDERAL DO RIO GRANDE DO SUL, 2017, não paginado).

O salãozinho, estando ligado à universidade, não passa ao largo de regulações que levam tais características a serem desenvolvidas, o que acaba por envolver, então, não apenas os professores universitários e das escolas. As crianças que participam do salãozinho também se veem envoltas em atividades em que são convocadas a competir, a transformar suas aprendizagens em investimento, a serem adaptáveis, móveis, capazes de encontrar soluções para suas dúvidas, de assumir riscos e de suportar estresse. E tudo isso ocorre antes mesmo do dia da apresentação do trabalho.

Nos pôsteres utilizados para a apresentação de pesquisas no salãozinho, as regras presentes no regulamento do Salão UFRGS Jovem regulam, se não o modo como as pesquisas são conduzidas, pelo menos como devem ser apresentadas:

\section{Curiosidades Sobre o Corpo Humano}

\section{Nosso grupo tinha várias dúvidas sobre o corpo humano:}

Os ossos são feitos de pedra branca?

Como ficam os ossos dentro quando quebram?

Como nascem os bebês?

\section{Para descobrir as respostas realizamos várias atividades.}

Pesquisamos em livros sobre o corpo humano e sobre os bebês.

Também visitamos o Laboratório de Ciências do colégio e o Laboratório de Geologia da UFRGS.

\section{Descobertas:}

Descobrimos que os ossos são feitos de cálcio.

Na geologia conhecemos uma pedra que é feita de cálcio.

Quando quebramos um osso o médico coloca um gesso para ele se recuperar, e existe uma "cola" natural dentro dos ossos.

Aprendemos que os bebês podem nascer de duas maneiras: cortando a barriga e pela vagina. Construímos uma maquete para visualizar melhor as partes do Corpo Humano.

Nossa pesquisa ainda não terminou e, agora, estamos estudando sobre o cérebro. 


\section{Projeto Astros do Universo}

\section{Nossas perguntas de investigação foram:}

Por que os planetas flutuam?

Por que as pessoas não caem da Terra?

Como é a Terra por dentro?

Do que são feitas as roupas dos astronautas?

\section{Nossos procedimentos de investigação incluíram:}

Realização de experiências, construção de maquetes, leituras de livros e buscas na internet. Nossos resultados foram:

- aprendemos que os planetas estão sob ação gravitacional uns dos outros e percorrem trajetórias que podem ser estudadas; os planetas parecem flutuar em suas órbitas;

- descobrimos que nós não caímos da Terra porque a força da gravidade nos atrai em direção ao chão;

- aprendemos que dentro da Terra há camadas de rochas sólidas e, até hoje, de materiais incandescentes;

- achamos que a roupa dos astronautas é parecida com a dos mergulhadores; as roupas espaciais do passado eram mais pesadas e bem diferentes das atuais.

\section{O criatório de mosquitos}

\section{Justificativa:}

No caminho do refeitório, ao lado da cancha de futebol, no Colégio de Aplicação da UFRGS, havia um entulho de materiais descartados. Eram pedaços de ventiladores, aparelhos de ar condicionado, mesas, cadeiras e lonas.

O entulho chamou a atenção dos alunos do $2^{\circ}$ ano, que passaram a observá-lo todos os dias.

\section{Metodologia:}

Além das observações fortuitas os alunos fizeram um trabalho sistemático de descrições, comparações, classificações, seriações, levantamento de ideias provisórias, experimentos e discussões.

\section{Primeiras curiosidades:}

- Origem dos materiais;

- Responsáveis pelo descarte;

- Motivo do descarte;

- Impacto ambiental;

- Água da chuva represada nas lonas.

Primeiras investigações:

- Responsabilidade da escola e do departamento de patrimônio;

- Legislação Municipal;

- Deterioração dos materiais e da água parada.

Larvas de insetos?

Primeiros resultados: 
Nesse acompanhamento sistemático da água, foram registradas as ocorrências e foi verificado que, com a chuva frequente, fazia-se a renovação da água e, no espaço de uma semana sem chuva, surgiam larvas.

\section{Experiências:}

As larvas foram coletadas, enviadas para o Laboratório de Biologia da CAp/UFRGS, tendo sido observadas ao microscópio. Depois, foram depositadas num recipiente, com tampa de tule, para a observação evolutiva. Os alunos consultaram a bióloga Profa. Dra. Rosane Nunes (CAp/UFRGS); as imagens do material indicavam a presença de espécies variadas de mosquitos, além do Aedes aegypti.

\section{Larvas de Mosquitos!}

\section{Conclusões e descobertas:}

- Há várias espécies de mosquitos;

- O Aedes aegypti é o mosquito que pode transmitir doenças como a dengue, caso esteja infectado.

- A chuva renova a água rasa que está represada.

- A água represada alimenta insetos e animais, além de ser ambiente adequado para desova de peixes e insetos.

- O ciclo de vida do mosquito é: ovo, larva, pupa e adulto e tem duração de aproximadamente uma semana.

- A fêmea bota até 300 ovos.

- O ovo leva, em média, 48h para se desenvolver e se transformar em embrião.

- A larva se alimenta de fungos e produtos orgânicos.

- A larva tem um respirador no final de cauda que parece uma antena.

- O mosquito dura em média 35 dias.

- Os ovos do mosquito aguentam vivos, no seco, até um ano. Quando o local é umedecido novamente, eclodem.

\section{Providências:}

- DePat/UFRGS está providenciando o registro e a retirada dos materiais;

- SMAN orientou a escola;

- Mobilização pelo Meio Ambiente. ${ }^{6}$

Os textos dos dois primeiros pôsteres transcritos apresentam as perguntas da pesquisa, a metodologia empregada e os resultados alcançados com o trabalho investigativo. Já o terceiro texto, além das etapas presentes nos primeiros, inclui a descrição mais detalhada da justificativa, das primeiras curiosidades, das primeiras investigações, dos primeiros resultados, das experiências (como método de investigação) e das providências suscitadas pelo estudo. $\mathrm{O}$ terceiro texto foi um dos premiados, sendo considerado o destaque no Salão UFRGS Jovem de 2011 (UNIVERSIDADE FEDERAL DO RIO GRANDE DO SUL, 2011).

Vale fazer um adendo em relação à questão da avaliação dos trabalhos considerados destaque no salãozinho. Esteban (2008) afirma que a avaliação tem sido 
confundida com a possibilidade de mensurar os conhecimentos adquiridos pelos estudantes, considerando o que foi ensinado pelo professor. No entanto, quando falamos em pedagogia de projetos - o que não seria o mesmo, mas apresentaria, num dizer wittgensteiniano, "semelhanças de família" entre o que nomeamos hoje como trabalhos de IC nos anos iniciais -, tiramos os pontos de apoio de procedimentos e instrumentos de avaliação que comparam o desempenho dos alunos ao resultado estimado. Torna-se comum o uso da comparação, que visa a gerar uma medida, traduzida em nota ou conceito, para informar o quanto o estudante se aproximou daquilo que era desejado no planejamento do ensino (ESTEBAN, 2008). A escolha de destaques pela Comissão de Avaliação do Salão UFRGS Jovem é um tipo de avaliação classificatória que posiciona estudantes e escolas de diferentes modos.

No caso do salãozinho, a avaliação que oferece uma premiação àqueles que tiverem um melhor desempenho em relação ao texto construído para o pôster e à apresentação oral realizada leva em conta somente resultados, visto que os avaliadores - que não fazem parte do processo pedagógico da construção do trabalho de IC - somente podem ter acesso ao momento final do estudo. Nesse sentido, podemos dizer que esse tipo de avaliação, ainda que até certo ponto produtiva, fomenta um clima de competição, um dos elementos centrais para a inserção dos sujeitos na cultura do empreendedorismo, associada, como sabemos, à lógica neoliberal.

Para Gadelha (2009), atualmente, verifica-se a existência de um tipo de governamentalidade pervasiva, que intenta programar estrategicamente atividades e comportamentos dos indivíduos. Uma governamentalidade que regula modos de sentir, agir, pensar e posicionar-se frente a si e ao mundo a partir de determinados processos e políticas de subjetivação: "novas tecnologias gerenciais no campo da administração (management), práticas e saberes psicológicos voltados à dinâmica e à gestão de grupos e das organizações, propaganda, publicidade, marketing, branding, 'literatura' de autoajuda, etc." (GADELHA, 2009, p. 151). Disso resulta o estabelecimento dos princípios econômicos (de mercado) como princípios normativos de toda a sociedade (GADELHA, 2009). Dessa maneira, a sociedade de consumo transmuta-se em uma sociedade de empresa, o que induziria "os indivíduos a modificarem a percepção que têm de suas escolhas e atitudes referentes às suas próprias vidas e às de seus pares, de modo a que cada vez mais estabeleçam entre si relações de concorrência" (GADELHA, 2009, p. 151, grifo do autor).

Feitas tais observações, podemos notar que apresentar trabalhos em eventos como o salãozinho se insere na lógica de mercado que fomenta relações de concorrência entre os indivíduos. Assim, construir um pôster com um texto que corresponde - da maneira mais fiel - ao que se propõe no regulamento aumenta substancialmente a possibilidade de agregar o título de destaque a uma pesquisa. Ao 
observarmos as normas presentes em um tutorial disponibilizado no site do Salão UFRGS Jovem 2012 para a elaboração de resumos, podemos dizer que o texto do terceiro pôster se aproxima mais do modelo preconizado:

2) Construindo o resumo

Um resumo deve conter as seguintes informações:

- Objetivo

- Justificativa

- Definição do objeto de estudo

- Metodologia

- Resultados (ainda que parciais)

- Conclusões

Tais informações são imprescindíveis, isto é, não podem faltar no resumo. Em geral, estão introduzidas por expressões específicas. Abaixo apresentamos alguns exemplos.

Objetivo ou objetivos:

- Este trabalho tem o objetivo de apresentar/tratar/expor/abordar...

- O propósito deste trabalho é apresentar/tratar/expor/abordar...

[...]

Justificativa:

- Ajustificativa para desenvolver o presente trabalho/experimento deve-se ao fato de que... [...]

Definição do objeto de estudo:

- Entende-se/Entendemos a energia solar como a energia produzida por...

Metodologia:

- A metodologia do trabalho/O experimento seguiu as seguintes etapas...

- Para atingir o(s) objetivo(s) proposto(s), foram seguidas as etapas: a)...; b)...

- Em primeiro lugar, apresenta-se/apresentamos... Em seguida, discute-se/discutimos... Finalmente, trata-se/tratamos...

Resultados:

- Os resultados/Os dados indicam/apontam que...

- Como resultado(s) parcial(is)/geral(is) destacamos/destaca-se/ressaltamos/ressalta-se [...]

Conclusões:

- Como conclusões preliminares, podemos/pode-se ressaltar/apontar/indicar que [...] (UNIVERSIDADE FEDERAL DO RIO GRANDE DO SUL, 2012).

É possível perceber que não se exige apenas uma descrição das etapas do trabalho dentro de um padrão de cientificidade. O tutorial que acompanha o regulamento prescreve também como e com quais palavras se deve narrar a pesquisa realizada. Pensando em uma clave foucaultiana, podemos dizer que a exigência da descrição - e, por conseguinte, da utilização - das etapas do método científico empregado na pesquisa realizada pelas crianças significa assegurar que o que está sendo dito no pôster apresentado está no domínio do verdadeiro, pois segue "as regras de uma 'polícia' discursiva" que deve ser reativada em cada um de nossos discursos (FOUCAULT, 2001, p. 35). 


\section{Método científico para todos}

Impressionada com o modelo adotado por escolas locais nos EUA, Celicina B. Azevedo escreveu a obra Metodologia científica ao alcance de todos. Seu objetivo, como destacado anteriormente, era disseminar a ideia de que o trabalho com a metodologia científica deveria ser expandido dos laboratórios em que atuam pesquisadores para todas as salas de aula, inclusive as de educação infantil. Em sua obra, Azevedo explica que escreveu o livro por acreditar "[...] que um estudante - do ensino fundamental à pós-graduação - pode aplicar o método científico nos seus trabalhos escolares sem que para tanto necessite ter profundos conhecimentos científicos" (AZEVEDO, 2013, p. XVII).

Para a autora, conforme os indivíduos vão crescendo, deixam de fazer perguntas, por medo de serem ridicularizados, com isso, passam a ser menos curiosos. Aprender a pensar, então, teria a ver com "dar asas à imaginação", "não impor limites ao pensamento", "pensar qualquer coisa, por mais absurda que ela possa parecer", pois, "pensar sem bloqueios é muito importante para ser um cientista" (AZEVEDO, 2013, p. 5). Entretanto, é necessário que esse pensar esteja circunscrito aos ditames do método científico, isto é, o pensar precisa estar subordinado à racionalidade científica da modernidade. Azevedo explica, inclusive, como devem ser feitas as perguntas: "[...] você precisa ser mais objetivo na sua pergunta, isto é, a pergunta deve ser clara e precisa, por exemplo: 'Quais doenças parasitárias incidem com maior frequência nas crianças da sua cidade?"' (AZEVEDO, 2013, p. 6, grifo nosso). E complementa dizendo: "observe que a pergunta deve ter uma solução possível, isto é, por meio da questão formulada você deve chegar a uma resposta [...]" (AZEVEDO, 2013, p. 6).

Apesar de argumentar que aprender a pensar seria o primeiro passo para se fazer pesquisa e estaria fortemente relacionado a "ter mais coragem de emitir nossa opinião sobre as coisas" (AZEVEDO, 2013, p. 4), em seu texto, a autora mostra como alguém que vai fazer uma pesquisa deve formular suas perguntas e, desse modo, como deve pensar suas curiosidades. Ao mesmo tempo, mostra que as curiosidades que "valem a pena" são aquelas que têm uma solução possível. Segundo a autora, também não basta saber formular a pergunta: "você precisa também formular uma possível resposta por meio de uma proposição, isto é, uma frase que possa ser declarada falsa ou verdadeira após uma investigação" (AZEVEDO, 2013, p. 7). Ela define o método científico como "um processo rigoroso pelo qual são testadas novas ideias acerca de como a natureza funciona" (AZEVEDO, 2013, p. 11).

Para Henning (2007), o método científico é caracterizado pela pretensão à universalidade dos conhecimentos por meio da ciência, sendo considerado na mo- 
dernidade a única forma de constituir conhecimentos válidos. É possível perceber que seus vestígios ainda hoje marcam forte presença, especialmente no contexto escolar. Observar e experienciar foram, desde a modernidade, afirmando-se como as premissas que possibilitavam transformar informações em conhecimentos científicos (HENNING, 2007). Assim, "o que suportasse o teste do Método Científico era então considerado válido em qualquer parte do mundo, já que o princípio básico era a universalidade dos conhecimentos verdadeiros" (HENNING, 2007, p. 168).

A ideia de aplicar o método científico na escola não é algo novo, guardando semelhanças de família com o movimento "escolanovista", tal qual defendido por Dewey. Em suas formulações, o filósofo estadunidense defendia o uso do método científico na sala de aula desde cedo. Para ele, era "correto o princípio educacional de que os alunos devem ser introduzidos ao estudo das ciências e que devem ser iniciados em seus fatos e leis através do conhecimento de suas aplicações sociais na vida cotidiana" (DEWEY, 2010, p. 83). Isso possibilitaria, segundo Dewey, não apenas a compreensão da própria ciência, mas também dos problemas econômicos e industriais da sociedade de seu tempo. Em defesa do uso das práticas presentes nos laboratórios na sala de aula, argumentava que processos similares aos estudados nos laboratórios e institutos de pesquisa deveriam fazer parte do cotidiano da escola, ainda que guardando suas especificidades frente ao público escolar (DEWEY, 2010). O método científico, para Dewey (2010), seria o fundamento para o professor - independentemente da faixa etária em que atuasse - organizar o trabalho em sala de aula, tendo por base a experiência.

\section{Considerações finais}

Podemos inferir, então, com base no material empírico analisado e nas teorizações estudadas, que a IC desejável a ser implementada nas escolas de educação básica parece prestar-se a isto: treinar, educar e exercitar cada parte do corpo de potenciais candidatos a carreiras científicas. Isso pressupõe condicionar os sentidos dos sujeitos, que devem agir, sentir, pensar e pesquisar como cientistas. Num dizer wittgensteiniano, trata-se de ensinar os sujeitos a "seguirem regras" (WITTGENSTEIN, 1999, I. F. § 199).

Assim, entendo que a IC na escola visa a ensinar os indivíduos a "seguir regras" da gramática científica, ou seja, hábitos (costumes, instituições) próprios da ciência. No entanto, cabe destacar que, mesmo tendo sido produzidos por cientistas e experts, ao serem usados na escola, esses manuais que "ensinam a seguir regras" são ressignificados. Ao passar pelo filtro da gramática escolar, o conhecimento científico, assim como o método científico, já não são os mesmos dos cientistas. 
Como nos mostram Knijnik e Wanderer (2013) em pesquisa sobre o Programa Escola Ativa (PEA), se distintas formas de vida apresentam diferentes gramáticas, as regras, ao serem trasladadas de uma para outra, assumem outra configuração, mais próxima da configuração da forma de vida de chegada. Assim, a IC que acontece na escola, ainda que tenha semelhanças de família com aquela que se efetua na universidade, já não é a mesma. O método científico, por sua vez, diferentemente do que é apregoado em geral, ao instalar-se entre as práticas escolares, torna-se prenhe de outras marcas, bem diferentes das que o caracterizaram nos laboratórios ou entre os cientistas.

Outro ponto relevante a destacar é que, mesmo estando presente nos materiais analisados nesta pesquisa, enunciados que apregoam que pensar cientificamente significa "remover obstáculos de nosso pensamento", "pensar de forma criativa" e "fazer todas as perguntas que queremos fazer" podem ser problematizados. Pensar em ciências não é pensar tão livremente. Significa pensar de acordo com as regras que conformam a sua gramática. A curiosidade, especialmente a curiosidade infantil, tão destacada no material escrutinado, ao ser delimitada pelas regras da gramática científica e, por conseguinte, pelo método científico escolar, acaba sendo regulada.

Em síntese, mais do que formar sujeitos capazes de pensar e agir de forma livre e criativa, a IC refere-se primeiramente ao disciplinamento do corpo e dos sentidos dos sujeitos, que devem aprender a ver, sentir, ouvir, cheirar e tocar - enfim, seguir regras - como cientistas. Em segundo lugar, refere-se ao direcionamento da conduta dos alunos, pensados na clave do cidadão cosmopolita de Popkewitz, Olsson e Petersson (2009), que deve aprender a aprender permanentemente, fazendo as "perguntas certas" a tudo que faz parte do cotidiano, de preferência, desde a mais tenra idade. E, em terceiro lugar, diz respeito ao modo como se conduzem as investigações que visam à elucidação das perguntas formuladas: com o uso do método científico. Portanto, é possível concluir que a IC realizada nos anos iniciais do ensino fundamental visa a subjetivar os indivíduos de determinado modo.

\section{Notas}

1 No original: "Who would question the need for scientists, engineers and mathematicians for producing the great technological progress that has made the world reach this high point of advancement $\square$ and decay, as well? The idea that mathematics $\square$ as well as science $\square$ with all its applications in technology is the motor for achieving the promises of Modernity and that, therefore, their teaching and learning are central to the constitution of massive school systems is as old $\square$ or new $\square$ as the end of the 19th century".

2 "O Salão UFRGS Jovem, evento que integra o Salão UFRGS, é uma atividade de cunho científico e tecnológico-cultural, a qual promove a interlocução entre os alunos da Educação Básica e da Educação Profissional e Técnica de Nível Médio e a comunidade em geral, a partir da exposição das pesquisas desenvolvidas no ambiente educacional" (UNIVERSIDADE FEDERAL DO RIO GRANDE DO SUL, 2017, não paginado). 
3 No original: "the social authority ascribed to particular agents and forms of judgement on the basis of their claims to possess specialized truths and rare powers".

4 No original: "we contend that the self-regulating capacities of subjects, shaped and normalized in large part through the powers of expertise, have become key resources for modern forms of government and have established some crucial conditions for governing in a liberal democratic way".

5 De modo sintético, Borges (2007) considera que Descartes entendia que a busca do conhecimento passava por um método considerado infalível. Tal método baseava-se no modelo matemático, deixando de lado a percepção sensorial, ao que ele atribuía a ocorrência de erros (BORGES, 2007). Descartes pensava ser necessário pôr em curso apenas uma investigação intelectual, separando mente e matéria e acreditando na possibilidade de descrição objetiva do mundo material, sem referir o observador humano (BORGES, 2007). Já Galileu também supunha a existência de uma ordem matemática no mundo, mas buscou testá-la de vários modos, inclusive com "experiências de pensamento". Assim, reuniu a observação, a razão e a experiência para interpretar os fenômenos físicos (BORGES, 2007). Bacon, por sua vez, defendia a ideia de que os fenômenos físicos devem ser estudados sem a interferência do observador. Sua proposta era a de um método que vai do particular ao geral, considerando a experimentação o único caminho válido para 0 estudo da natureza (BORGES, 2007).

${ }_{6}$ Trata-se das transcrições de alguns dos pôsteres encontrados na sala de professores, a que me referi anteriormente.

\section{Referências}

AZEVEDO, Celícina Borges. Metodologia científica ao alcance de todos. 3. ed. Barueri: Manole, 2013.

BORGES, Regina M. R. Em debate: cientificidade e educação em ciências. 2. ed. Porto Alegre: EDIPUCRS, 2007.

BRASIL. Ministério da Ciência e Tecnologia. Livro verde: ciência, tecnologia e inovação. Brasília, DF: MCT, 2001.

COLÉGIO DE APLICAÇÃO DA UFRGS. Iniciação científica. Porto Alegre, 2017. Disponível em: <http://capunialfas.blogspot.com.br/p/iniciacao-cientifica.html>. Acesso em: 30 nov. 2017.

COLÉGIO MONTEIRO LOBATO. Matrículas. Porto Alegre, 2017. Disponível em: <http://colegiomonteirolobato.com.br/matriculas/\#hero_with_parallax_5>. Acesso em: 30 nov. 2017.

COLÉGIO MARISTA CHAMPAGNAT. Diferenciais. Porto Alegre, 2017. Disponível em: <http:// colegiomarista.org.br/champagnat/diferenciais/anos-iniciais>. Acesso em: 30 nov. 2017.

DELEUZE, Gilles. Foucault. São Paulo: Brasiliense, 2006.

DEWEY, John. Experiência e educação. Rio de Janeiro: Vozes, 2010.

DÍAZ, Esther. Investigación básica, tecnología y sociedad: Kuhn y Foucault. In: DÍAZ, E. (Org.). La posciencia: el conocimiento científico en las postrimerías de la modernidad. 3. ed. Buenos Aires: Biblos, 2007. p. 63-82.

DISCOVERY KIDS LATIN AMERICA. Sid, o cientista. Miami, 2012. Disponível em: <http://discoverykidsbrasil.uol.com.br/personagens/sid-o-cientista/ personagens/sid/>. Acesso em: 24 ago. 2012.

ESTEBAN, Maria Teresa. Pedagogia de projetos: entrelaçando o ensinar, o aprender e o avaliar à democratização do cotidiano escolar. In: SILVA, Janssen Felipe; HOFFMANN, Jussara; ESTEBAN, Maria Teresa (Org.). Práticas avaliativas e aprendizagens significativas: em diferentes áreas do currículo. Porto Alegre: Mediação, 2008. 
FERREIRA, Anna Rachel. Foco na pesquisa. Revista Nova Escola, São Paulo, a. 28, n. 265, p. 36-44, set. 2013.

FISCHER, Rosa Maria Bueno. Trabalhar com Foucault: arqueologia de uma paixão. Belo Horizonte: Autêntica, 2012.

FOUCAULT, Michel. História da sexualidade I: a vontade de saber. Rio de Janeiro: Graal, 1999.

FOUCAULT, M. Arqueologia do saber. Rio de Janeiro: Forense Universitária, 2002.

FOUCAULT, M. A Ordem do discurso: aula inaugural no Collège de France, pronunciada em 2 de dezembro de 1970. 14. ed. São Paulo: Loyola, 2001.

FOUCAULT, Michel. Microfísica do poder. Org. Trad. Roberto Machado. Rio de Janeiro: Graal, 2008.

FOUCAULT, Michel. Ditos e escritos IV: estratégia, poder-saber. 3. ed. Rio de Janeiro: Forense Universitária, 2012.

GADELHA, Sylvio. Biopolítica, governamentalidade e educação: introdução e conexões a partir de Michel Foucault. Belo Horizonte: Autêntica, 2009.

HENNING, Paula C. Profanando a ciência: relativizando seus saberes, questionando suas verdades. Currículo sem Fronteiras, v. 7, n. 2, p. 158-184, jul./dez. 2007.

KNIJNIK, Gelsa; WANDERER, Fernanda. Programa escola ativa, escolas multisseriadas do campo e educação matemática. Educação e Pesquisa, São Paulo, v. 39, n. 1, jan./mar. 2013.

MACEDO, Beatriz; KATZKOWICZ, Raquel. Educação científica: sim, mas qual e como? In: SASSON, Albert et al. Cultura científica: um direito de todos. Brasília, DF: UNESCO, 2003. p. 67-86.

MILLER, P.; ROSE, N. Governing economic life. Economy and Society, Londres, n. 19, v. 1, p. 1-31, 1990. Disponível em: <http://stateinafrica.files.wordpress.com/2008/02/miller-rose-1990. pdf>. Acesso em: 21 abr. 2013.

MOREIRA, Marco Antônio; OSTERMANN, Fernanda. Sobre o ensino do método científico. Caderno Brasileiro de Ensino de Física, Florianópolis, v. 10, n. 2, p. 108-117, ago. 1993. Disponível em: <https://periodicos.ufsc.br/index.php/fisica/article/view/7275>. Acesso em: 10 nov. 2017.

NOGUERA-RAMÍREZ, Carlos Ernesto. Pedagogia e governamentalidade ou da modernidade como uma sociedade educativa. Belo Horizonte: Autêntica, 2011.

PARAÍSO, M. A. O autogerenciamento de docentes em sua formação e em seu trabalho. Educação e Pesquisa, São Paulo, v. 31, n. 2, p. 173-188, maio/ago. 2005.

POPKEWITZ, Thomas S.; OLSSON, Ulf; PETERSSON, Kenneth. Sociedade da aprendizagem, cosmopolitismo, saúde pública e prevenção à criminalidade. Educação \& Realidade, Porto Alegre, v. 34, n. 2, p. 73-79, maio/ago. 2009.

RIPOLL, D.; WORTMANN, M. L. C. Aprendendo a amar a ciência na animação: "Sid, o cientista”. In: SEMINÁRIO DE PESQUISA EM EDUCAÇÃO DA REGIÃO SUL - ANPED SUL, 9, 2012, Caxias do Sul. Anais... Caxias do Sul: UCS, 2012. p. 1-15. 
SILVA, Carlos Eduardo Lira. Ideias sobre a natureza da ciência e suas repercussões na estruturação de uma prática de iniciação científica infantil. 2008. Dissertação (Mestrado em Educação em Ciências e Matemática) - Núcleo de Pesquisa e Desenvolvimento da Educação Científica e Matemática, Universidade Federal do Pará, Belém, PA, 2008.

UNIVERSIDADE FEDERAL DO RIO GRANDE DO SUL. Cerimônia de encerramento do Salão UFRGS 2011. Porto Alegre, 2011. Disponível em: <http://www6.ufrgs.br/ salaoufrgs2011/>. Acesso em: 03. jun. 2012.

VII Salão UFRGS Jovem. Porto Alegre, 2012. Disponível em: <http://www.ufrgs.br/ salaoufrgs2012/o-salao-ufrgs-2012/vii-salao-ufrgs-jovem>. Acesso em: 11 set. 2013.

Regulamento do I Salão UFRGS Jovem. Porto Alegre, 2013. Disponível em: <http://www. propesq.ufrgs.br/sic1/folderufrgsjovem.php>. Acesso em: 25 abr. 2013.

. Salão UFRGS Jovem. Porto Alegre, 2017. Disponível em: <http://www.ufrgs.br/propesq1/ ufrgsjovem2017/wp-content/uploads/2017/06/Regulamento-2017.pdf>. Acesso em: 30 nov. 2017.

VALERO, Paola. Mathematics for all and the promise of a bright future. Papers for the CERME 8 Conference, Turkey, 2013. p. 1-10. Disponível em: <http://vbn.aau.dk/files/76731132/WG10_Valero.pdf $\geq$. Acesso em: 10 out. 2013.

WANDERER, Fernanda; SCHEFER, Maria Cristina. Metodologias de pesquisa na área da educação (matemática). In: WANDERER, Fernanda; KNIJNIK, Gelsa (Org.). Educação matemática e sociedade. São Paulo: Livraria da Física, 2016. p. 33-50.

WITTGENSTEIN, Ludwig. Investigações filosóficas. São Paulo: Nova Cultural, 1999.

ZULIANI, Renata Duarte. Professores das séries iniciais do ensino fundamental e as feiras de ciências. 2009. Dissertação (Mestrado em Educação para a Ciência e Matemática) - Faculdade de Ciências, Universidade Estadual Paulista, Bauru, SP, 2009. 